\title{
Distribution and prevalence of ticks and tick-borne disease on sheep and cattle farms in Great Britain
}

\author{
Katie Lihou ${ }^{1 *}$, Hannah Rose Vineer ${ }^{2}$ and Richard Wall ${ }^{1}$
}

\begin{abstract}
Introduction: The most abundant and widespread tick species in Great Britain, Ixodes ricinus, is responsible for the transmission of a range of pathogens that cause disease in livestock. Empirical data on tick distribution and prevalence are required to inform farm management strategies. However, such data are largely unavailable; previous surveys have been rare and are usually relatively localised.

Methods: A retrospective questionnaire survey of farmers was used to assess the reported prevalence of ticks on livestock across Great Britain. Spatial scan statistics and kernel density maps were used to assess spatial clustering and identify areas of significantly elevated risk, independent of the underlying distribution of respondents. Logistic regression models were used to identify risk factors for tick presence.

Results: Tick infection risk to livestock is shown to be spatially aggregated, with areas of significantly elevated risk in north Wales, northwest England and western Scotland. Overall, the prevalence of farms reporting tick presence was $13 \%$ for sheep farms and $6 \%$ for cattle farms, but in "hot spot" clusters prevalence ranged between $48-100 \%$. The prevalence of farms reporting tick-borne disease overall was $6 \%$ for sheep and $2 \%$ for cattle, but on farms reporting ticks, prevalence was $44 \%$ and 33\% for sheep and cattle farms, respectively. Upland farming, larger flock sizes, region and the presence of sheep on cattle farms were all significant risk factors for tick presence.

Conclusions: These data have important implications for assessing both the risk of tick-borne disease in livestock and optimising approaches to disease management. In particular, the study highlights the need for effective livestock tick control in upland regions and the southwest, and provides evidence for the importance of sheep as tick maintenance hosts.
\end{abstract}

Keywords: Disease risk, Livestock, Pathogen, Ixodes ricinus, TBD management

\section{Background}

In livestock husbandry, ticks are important both as direct blood-feeding parasites and as vectors of a range of production-limiting pathogens with economic and welfare impacts on the livestock industry through reduced production and animal mortality $[1,2]$. The most widespread tick vector of livestock pathogens in northern Europe is

\footnotetext{
*Correspondence: kl14574@bristol.ac.uk

${ }^{1}$ School of Biological Sciences, University of Bristol, Bristol BS8 1TQ, UK

Full list of author information is available at the end of the article
}

Ixodes ricinus [3, 4], with clinical cases occurring during the periods of tick activity, primarily from the spring through to autumn. Predicting the distribution and incidence of tick-borne disease (TBD) can be complex, since it depends on both the availability of hosts and abundance of questing ticks, which varies across seasons, years and regions [5], reflecting variations in local microclimate and habitat [6]. However, it is also affected by the prevalence of pathogens within co-occurring transmission hosts [7] and the immunity generated by prior exposure $[8,9]$.

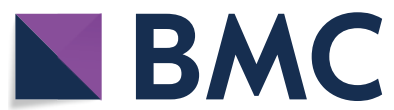

(c) The Author(s) 2020. This article is licensed under a Creative Commons Attribution 4.0 International License, which permits use, sharing, adaptation, distribution and reproduction in any medium or format, as long as you give appropriate credit to the original author(s) and the source, provide a link to the Creative Commons licence, and indicate if changes were made. The images or other third party material in this article are included in the article's Creative Commons licence, unless indicated otherwise in a credit line to the material. If material is not included in the article's Creative Commons licence and your intended use is not permitted by statutory regulation or exceeds the permitted use, you will need to obtain permission directly from the copyright holder. To view a copy of this licence, visit http://creativeco mmons.org/licenses/by/4.0/. The Creative Commons Public Domain Dedication waiver (http://creativecommons.org/publicdomain/ zero/1.0/) applies to the data made available in this article, unless otherwise stated in a credit line to the data. 
While $I$. ricinus is widespread in the UK, populations are highest in areas where the habitat, microclimate and host availability are conducive to high survival [10]. These are generally areas of rough grassland, heath, moorland and woodland with a moist vegetation layer, where the relative humidity remains above the critical value of $80 \%$, required to prevent desiccation $[3,10]$. These areas often have high populations of wild hosts, such as rabbits, deer or ground nesting birds and are unsuitable for crops, so can support only extensive livestock grazing [3, 11]. Sheep in particular are thought to be one of the most important host species for all I. ricinus life-cycle stages in pasture or moorland [12]. Control is difficult as I. ricinus is generally non-host specific, infecting a variety of mammals and birds and spending the majority of its life-cycle off-host in the environment [13].

For sheep in the UK, ticks are particularly important in the transmission of tick-borne fever (anaplasmosis), louping-ill virus (LIV) and tick pyaemia. Anaplasmosis is a widely dispersed disease throughout Europe and can be major problem in livestock production, affecting both sheep and cattle [14]. The bacterium, a ruminant-specific variant of Anaplasma phagocytophilum, infects granulocytes, which can result in secondary infections due to immunosuppression [15]. Transstadial transmission of A. phagocytophilum can occur, whereby the pathogen is transmitted from one tick developmental stage to the next. Louping-ill virus (LIV), also called infectious ovine encephalomyelitis, can also be transmitted by transstadial transmission. LIV is an acute viral disease which affects the brain and the nervous system caused by a flavivirus closely related to the causal agent of tick-borne encephalitis. Louping-ill has been reported from most regions in the north and west of the UK, but has not been found in central or east England [16]. Louping-ill has also been identified in Ireland and regions of France and Norway [17]. The disease is characterised by nasal discharge, fever, depression, ataxia, paralysis and coma, leading in many cases to death; morbidity in lambs can be up to $50 \%$ [18]. However, following early infection, lifelong immunity is sustained. Pyaemia results from the infection of lambs or sheep with Staphylococcus aureus. It is not directly transmitted by ticks, but $S$. aureus, usually found on the skin, may become pathogenic when transferred mechanically to the bloodstream via the bite of a tick. There is a strong association between tick-borne fever and pyaemia [19]. Pyaemia affects lambs born on, or newly introduced to, a tick infected area, and shows a peak in spring when tick abundance is high.

Regarding cattle in the UK, I. ricinus also transmits A. phagocytophilum and LIV, but importantly in some areas it is also a vector of Babesia divergens, the causal agent of redwater [2]. In the process of asexual division, intraerythrocytic Babesia cause lysis of erythrocytes, leading to haemoglobinaemia, haemoglobinuria and fever. In naïve adult hosts, infection may cause death within a few days. Milder forms of the disease, associated with juvenile or immune hosts, are characterized by fever and inappetence for a period of several days. In addition to transstadial transmission, Babesia is also transmitted via transovarial transmission within the tick, allowing the larvae, nymphs and adults of the next generation to transmit infection to cattle [2].

Despite the known range of tick-borne pathogens and concern over their impact on the welfare of livestock, there is very little quantitative information available about the prevalence of tick-borne disease in many areas of the UK. Previous systematic surveys in the UK have most usually been undertaken in the context of public health [20, 21], companion animal health [22-24], game birds [25], or by measuring tick abundance in the environment [26], which is not necessarily a good proxy for tick attachment risk [27]. Those studies of tick prevalence on livestock in the UK that have been undertaken, have usually been focussed on localised geographical regions with little area-wide context [28, 29]. Variability in sampling approach, time and context, also make reliable comparison between studies difficult. Furthermore, the fact that relatively few acaricidal pharmaceutical products are available with a label claim for efficacy against ticks in livestock, indicate that the control of ticks and TBD represents something of a neglected issue.

Appropriate strategies for tick and TBD management require an assessment of risk [30] and this necessitates up-to-date data on tick prevalence and distribution [31] in relation to livestock hosts. The aim of the work reported here, therefore, was to investigate the prevalence and spatial distribution of ticks and tick-borne disease reported in cattle and sheep in Great Britain and then to identify areas of elevated risk of tick attachment to livestock using spatial distribution modelling.

\section{Methods \\ Questionnaire survey}

A two-page retrospective postal questionnaire survey was sent to sheep and cattle farmers in Great Britain. The sample area was first stratified into 6 regions: Scotland, Wales, north, central, southwest and eastern England. A total of 7200 questionnaires were sent to a randomised selection of farms in each region sourced from a commercial database [32]. Questionnaires were only sent to farms meeting the following criteria: more than 50 sheep, or more than 20 beef cattle, or more than 30 dairy cattle, to avoid surveying smallholdings and 'hobby farmers', which may not be representative of commercial farms. Power analysis was used to obtain regional sample sizes 
to accurately estimate the proportion of cases in each region. The number of questionnaires sent out in each region, was based on the number of cattle or sheep holdings in each [33, 34], an estimated prevalence rate of $15 \%$, an estimated response rate of $30 \%$ (based on previous farm-based survey studies, e.g. [35, 36], a confidence level of $95 \%$ and a margin of error of 5\% (Win Episcope v.2.0; [37]). The questionnaire was sent out in November of 2018, and asked for general information about the holding and information about livestock numbers, tick presence and cases of TBD in the previous 12 months between November 2017 and October 2018, to control for temporal differences in tick abundance and distribution. The questionnaire contained separate sections for sheep and for cattle (see Additional file 1: Text S1).

The distribution of respondents was externally validated by qualitative comparison with the distribution of cattle and sheep holdings in the UK [38, 39]. Farm characteristics of respondents were externally validated by qualitative comparison with the ratio of dairy to beef farms [34] and the ratio of upland to lowland farms [40]. Questionnaires were also checked for internal consistency by removing questionnaires with missing tick presence/absence data and by qualitatively comparing monthly reported tick prevalence with expected temporal trends.

\section{Prevalence analysis}

Responses for sheep or cattle farms were analysed separately, except when a direct comparison was made between sheep and cattle in reported tick prevalence. Differences in tick prevalence (proportion of farms reporting tick presence compared to tick absence) between regions and between farm terrain types (upland/lowland) were tested using Chi-square in $\mathrm{R}$ (version 3.6.1; [41]) using the chisq.test function. If expected values were less than five, Monte Carlo simulated $P$-values were used [42]. All prevalence values are reported \pm their $95 \%$ confidence intervals.

\section{Spatial analysis}

Farm postcodes were used for spatial analysis of cases (reported tick presence) and controls (reported tick absence) and converted to latitude and longitude [43]. Deviation from complete spatial randomness (CSR) was assessed by plotting significance envelopes of the G function, based on Monte Carlo simulation (100 repeats; Gest function in the spatstat R package (v.1.60-1; [44]). To identify case "hot spots" (areas which contain a higher density of points than would be expected with CSR) whilst accounting for the underlying distribution of the data points, the spatial relative risk of a respondent reporting the presence of ticks was estimated from the relative densities of cases and controls using the risk function in the sparr R package (v.2.2-13; [45]). An adaptive bandwidth was used, to compensate for potential over-smoothing in dense areas, calculated symmetrically with respect to cases and controls [45]. Diggle's edge correction was applied [45]. Asymptotic tolerance contours of $P$-values were plotted to show statistically significant areas of elevated risk (tol.contour function in the sparr $\mathrm{R}$ package; [46]).

Spatial clustering was assessed on different spatial scales using envelopes of the L-function (a standardised version of the K-function), which calculates the number of data points within a specified radius of each point (Lest function in the spatstat $\mathrm{R}$ package). L-functions were compared between case and control points to detect whether case points were more clustered than clustering caused by the underlying point distribution. Clustering was assessed for significance using SaTScan ${ }^{\mathrm{TM}}$ [47], which uses Monte Carlo discrete spatial scan statistics to detect non-random clusters of cases, whilst adjusting for the underlying spatial distribution of the data points. A Bernoulli model was used as data were binary. Maximum cluster size was set to a radius of $150 \mathrm{~km}$ to prevent inappropriately large clusters.

\section{Risk factors}

Risk factors for tick presence were tested using multivariable logistic regression models, applied using the $\mathrm{glm}$ function in R with 'family = binomial'. Selected variables which met assumptions for logistic regression were first analysed using univariable logistic regression for continuous independent variables and Chi-square for categorical independent variables. Any variables with a $P$-value $<0.25$ were selected for multivariable analysis [48]. The number of variables included in the initial multivariable model did not exceed the frequency of the least common outcome (presence of ticks) divided by 10 [49]. Categorical variables were dummy-coded and the reference levels were selected as those with the lowest probability of reporting ticks [50]. The final models were selected using stepwise selection to minimise the AIC (Akaike information criterion) value. The variance inflation factor (VIF) was used to check that multicollinearity between explanatory variables was low $(<4)$, using the vif function in the car R package (v.3.0.5; [51]). Model accuracy was assessed using the area under the receiver operating curve (AUC) (AUROC function in InformationValue $\mathrm{R}$ package (v.1.2.3; [52]) which plots sensitivity (the true positive rate) against 1 - Specificity (the false positive rate) at different threshold values. Values range from 0.5 to 1.0 , with 1.0 depicting a perfect model, which would correctly detect $100 \%$ of both true and false positives. The threshold for sensitivity and specificity was selected 
to optimise both, by using maximum Youden's Index (optimalCutoff function in InformationValue R package). Odds ratios and confidence intervals were calculated as $\exp (\beta)$, where $\beta$ is the coefficient estimate and using profile likelihood confidence intervals (confint function in R), respectively, to assess the relative impact of variables in the final model on the reported presence of ticks.

\section{Results}

\section{Questionnaire respondents}

The overall questionnaire response rate was $13.4 \%(n=$ 964), with 926 respondents providing valid postcodes (906 of these were full postcodes, with the remaining 20 valid to at least district level). Respondent numbers were highest in the southwest of England and Wales, which is consistent with the distribution of sheep and cattle farms $[38,39]$. Of the total respondents, $17 \%(\mathrm{CI} \pm 2 ; n=159)$ farmed only sheep, $33 \%( \pm 3 ; n=316)$ farmed only cattle, and $51 \%( \pm 3)(n=489)$ farmed both. Of the farms with cattle, $72 \%( \pm 3 ; n=580)$ farmed beef, $13 \%( \pm 2 ; n=$ 104) farmed dairy, and $15 \%( \pm 3 ; n=121)$ farmed both. The majority of farms, $84 \%( \pm 2 ; n=810)$, were conventional and $5 \%( \pm 1 ; n=50)$ were organic, with $11 \%( \pm 2$; $n=104)$ unspecified. Of the respondents, $63 \%( \pm 3 ; n=$ $605)$ described their farms as being lowland, $31 \%( \pm 3$; $n=294)$ as upland, $3 \%( \pm 1 ; n=25)$ as both, and $4 \%( \pm$ $1 ; n=40)$ did not specify. The data were generally representative of the underlying holding population of England, Wales and Scotland, in terms of holding density [38, 39], ratio of dairy to beef farms [34] and ratio of upland to lowland farms [40]. Ticks were reported in all months (Fig. 1). The proportion of ticks reported each month followed a normal distribution from January to December with the highest proportion of reports during May-July. This is consistent with the unimodal peak of tick activity characteristic in environments with cold winters [10], so no questionnaires were excluded on the basis of temporal trends.

\section{Tick prevalence}

After internal validation, the total number of sheep farm respondents was 642 and the total number of cattle farm respondents was 797 . The overall prevalence of farms reporting tick presence was $13.2 \%(\mathrm{CI} \pm 2.6 ; n=85)$ for sheep farms and $6.2 \%( \pm 1.7 ; n=49)$ for cattle farms. Overall, the prevalence of sheep farms with reported tick presence was higher than the prevalence of cattle farms with reported tick presence $\left(\chi^{2}=18.41, n=1380, P<\right.$ 0.001 ). When stratified by region, the prevalence of sheep farms reporting ticks was higher than the prevalence of cattle farms reporting ticks in all regions, but this difference was only significant in Wales $\left(\chi^{2}=4.93, n=256, P\right.$
$<0.05)$ and the north of England $\left(\chi^{2}=8.97, n=368, P<\right.$ 0.01 ; Fig. 2).

The prevalence of farms reporting tick presence differed significantly between regions for both sheep farms $\left(\chi^{2}=20.17, n=648, P<0.01\right)$ and cattle farms $\left(\chi^{2}=\right.$ $15.35, n=805, P<0.05)$. The prevalence of sheep farms (as a percentage of the number of farms in each region) was highest in Scotland at 20.0\% $( \pm 8.0 \%, n=19)$ and Wales at $16.0 \%( \pm 6.6 \%, n=19)$ and lowest in east England at $4.1 \%( \pm 5.5, n=2)$ and central England at $2.2 \%$ $( \pm 3.1, n=2)$ (Fig. 2). The prevalence of cattle farms was highest in Scotland at 10.3\% $( \pm 5.5, n=12)$ and southwest England at $9.6 \%( \pm 4.8, n=14)$ and lowest in east England at $1.4 \%( \pm 2.8, n=1)$ and central England at $1.9 \%( \pm 2.65, n=2)$ (Fig. 2).

The prevalence of farms reporting tick presence was $24.3 \%( \pm 5.3 ; n=61)$ on upland sheep farms, compared to $4.3 \%( \pm 2.1 ; n=15)$ on lowland farms. For cattle farms, prevalence was $10.0 \%( \pm 3.8 ; n=24)$ for upland farms and $3.8 \%( \pm 1.7 ; n=19)$ for lowland farms.

\section{Spatial distribution of ticks}

$G$ function analysis showed that respondent density differed significantly from CSR, as would be expected due to the heterogeneous nature of underlying farm density. Comparison of the case/control L functions showed that case points (reported tick presence) were more clustered than control points (reported tick absence) at radii $>5$ $\mathrm{km}$ for sheep and $>7.5 \mathrm{~km}$ for cattle.

The relative risk of farmers (Fig. 3a) reporting sheep ticks and tolerance contours showed that north Wales, northwest England and western Scotland, were areas of statistically significantly elevated risk (Fig. 3a; $P<0.05$ ). Cases in these areas were also confirmed as significantly clustered by SaTScan ${ }^{\mathrm{TM}}$ analysis (Table 1).

Spatial heterogeneity in predicted relative risk was smaller for cattle ticks, but similar to the analysis for sheep farms, areas of statistically significantly elevated risk were identified in north Wales, northwest England and Scotland (Fig. 3b; Table 1). Although the reported prevalence of cattle tick cases was highest in southwest England, when considering case points on a more continuous geographical scale, taking into account the underlying distribution of respondents, cases were not found to be significantly clustered in this region.

\section{Risk factors for tick presence}

For sheep, variables included in the initial model, based on univariable analysis were: terrain type (upland/lowland), flock size, farm type (organic/conventional) and region, but farm type was eliminated from the model during stepwise selection. After farms with missing data 


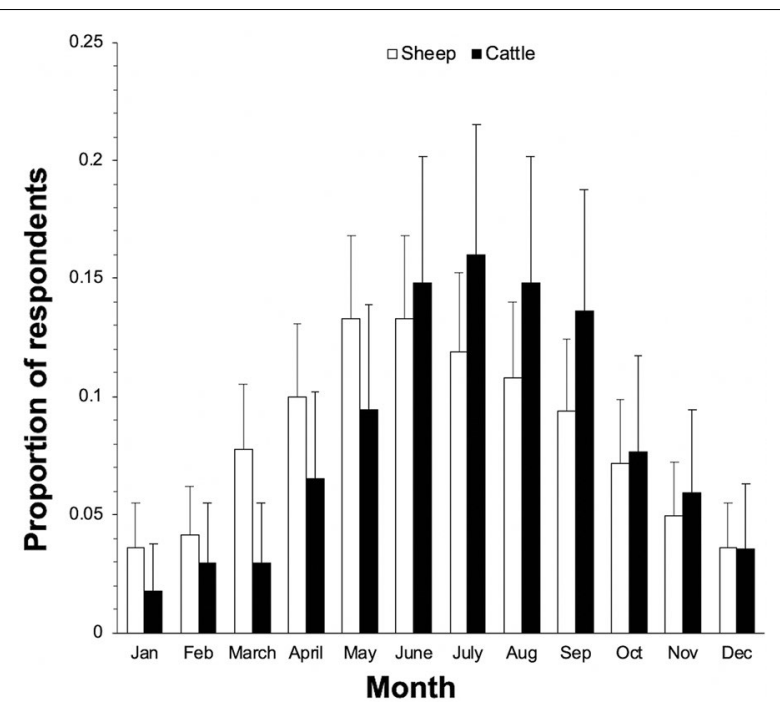

Fig. 1 Sheep and cattle farms reporting tick infestation in each month in a retrospective questionnaire survey in Great Britain as a proportion of the number of sheep or cattle respondents ( $\pm 95 \%$ confidence intervals)

were removed, 480 remained in the final model. The VIF was $<4$ for all variables in the final model. Significant risk factors for reported tick presence on sheep were upland terrain, larger flock sizes and being located in southwest England (Table 2; AUC $=0.77, \chi^{2}=480$, residual deviance $=305.4(d f=472)$, null deviance $=377.0(d f=$ 479)) (Table 2).

For cattle, variables included in the initial model, based on univariable analysis, were: terrain type (upland/lowland), livestock type (cattle only farm/cattle and sheep farm), cattle type (beef farm/dairy farm/both) and region, but cattle type was eliminated from the model during stepwise selection. After farms with missing data were removed, 711 remained in the final model. The VIF was $<4$ for all variables in the final model. Significant risk factors for reported tick presence on cattle were upland terrain, presence of sheep and being located in southwest England (Table 2; AUC $=0.73, \chi^{2}=711$, residual deviance $=285.5(d f=704)$, null deviance $=319.1(d f=$ 710)).

\section{Tick-borne disease (TBD)}

The prevalence of farms reporting at least one TBD case was $5.7 \%( \pm 1.8 ; n=37)$ for sheep and $2.0 \%( \pm 1.0 ; n$ $=16$ ) for cattle. Of those that reported finding ticks on their animals, $43.5 \%( \pm 10.5 ; n=37)$ of sheep respondents and $32.7 \%( \pm 13.1 ; n=16)$ of cattle respondents also reported having at least one TBD. Of farms reporting disease, $5.4 \%( \pm 7.3 ; n=2)$ of sheep disease cases and $18.8 \%( \pm 19.1 ; n=3)$ of cattle disease cases were reported

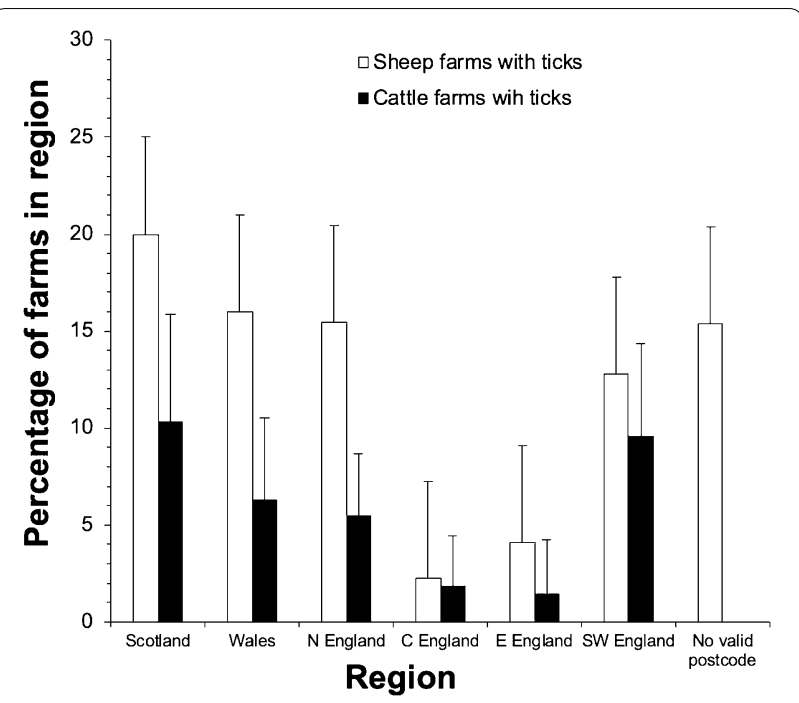

Fig. 2 The percentage of sheep farms and cattle farms in a retrospective questionnaire survey in Great Britain reporting tick infestation relative to the number of respondents in that region $( \pm$ 95\% confidence intervals)

to be diagnosed by a veterinarian or diagnostic laboratory. In sheep, the most common TBD was tick-borne fever $(4.2 \pm 1.5 \% ; n=27)$ (Fig. 4). In cattle, redwater was the most reported TBD $(1.2 \pm 0.8 \% ; n=10)$ (Fig. 4). The density of respondents reporting sheep disease was highest in Wales and northwest England and cattle disease in southwest England. Due to the low number of disease case points, it was generally not possibly to identify areas of significantly elevated risk; however, SaTScan ${ }^{\mathrm{TM}}$ did identify a significant cluster of tick pyaemia in sheep in northwest England and of redwater in cattle in southwest England (Table 3). Of sheep farm respondents reporting disease, $97.1 \%( \pm 5.4 ; n=34)$ were from upland farms. Of cattle farm respondents, $57.1 \%( \pm 24.3 ; n=8)$ were from upland farms.

\section{Discussion}

The spatial analysis approach used here identifies clusters, areas which contain a higher density of points than would be expected whilst accounting for the underlying distribution of the respondents to the survey. The distribution of tick infestation and tick-borne disease prevalence in sheep and cattle reported here are consistent with the known distribution of $I$. ricinus [22, 53, 54]. Overall, $13 \%$ of sheep farms and $6 \%$ of cattle farms reported that their animals had had ticks in the study year, but with areas of significantly higher prevalence in north Wales, northwest England and western Scotland. Livestock in these regions primarily graze upland pastures and this was a significant risk factor for tick 

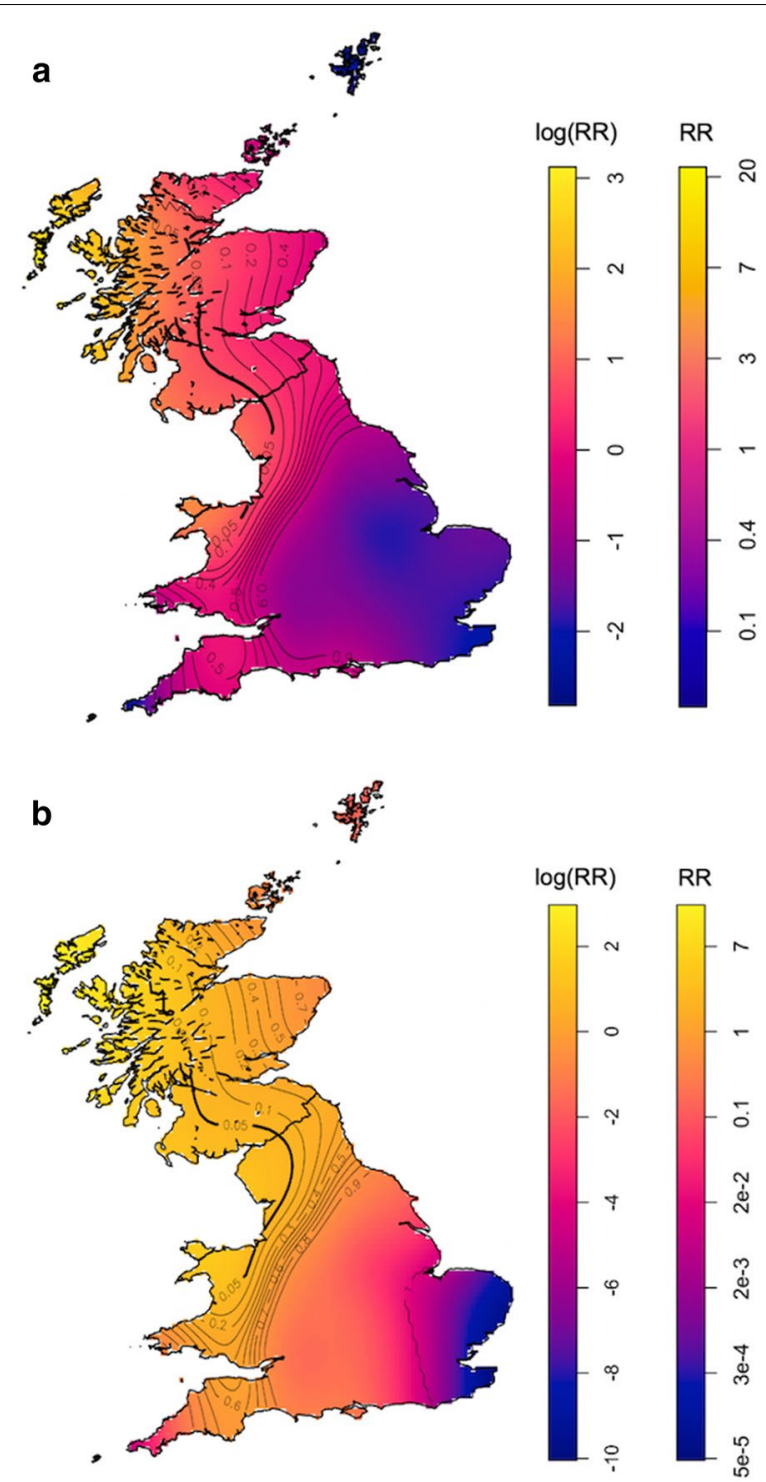

Fig. 3 Relative risk (RR) of farms reporting tick infestation in sheep (a) and cattle (b) in a retrospective questionnaire survey in Great Britain with tolerance contour lines overlain. Lighter colours indicate higher risk and areas with significantly higher risk $(P<0.05)$ shown by the bold contour. The colour scales show log and raw relative risk

presence. The prevalence of tick infestation on upland farms was higher than the national prevalence at $24 \%$ and $10 \%$ for sheep and cattle, respectively and the prevalence of ticks on farms in statistically significant "hot spot" clusters ranged between $48-100 \%$. Upland regions, which are classified by the EU as 'Less Favoured Areas' characterized by rough grazing, heathland and moorland [55], often contain a high density of questing ticks due to the combination of appropriate microclimates suitable for tick survival and abundant wildlife hosts $[12,56]$ and are therefore areas of high contact between livestock and ticks. Although tick populations can still be high in lowland regions, they are more limited by the lower availability of suitably humid microhabitats [57].

It is notable that for cattle the presence of sheep on the farm was a significant risk factor for tick infestation. Although deer are important hosts for ticks [25], especially in Scotland [58], sheep have been shown to maintain stable tick populations in upland regions, in the absence of other wildlife hosts, acting as hosts for all $I$. ricinus life-cycle stages $[12,59]$. Hence, sheep are able to act as important maintenance hosts for tick populations in upland areas. It was suggested by Evans [60] that on mixed farms, because sheep are turned out onto pasture earlier than cattle, sheep may be a particularly important food source for the early spring population of ticks and the presence of sheep co-grazing may increase the tick population, but in some circumstances may also help to reduce the infestation on cattle.

Although under some conditions there may be a positive relationship between pathogen prevalence and tick density, this is highly variable [61] and tick presence or absence has been found to be a better predictor of pathogen transmission risk than tick abundance [62]. Therefore, risk based upon presence and absence data gives valuable information on the areas where livestock are most at risk from tick-borne disease, although presentation of clinical cases will also depend upon population immunity. Host density is also important for disease transmission, as has been found with LIV models [1] and the areas of elevated risk for tick presence are also generally areas of high livestock density $[38,39]$. Although there were too few disease cases in the present study to allow relative disease risk to be mapped, the density of reported disease cases generally mirrored the density of reported tick cases. However, an exception was redwater in cattle, where a significant cluster of cases was found in southwest England. In 2006, Barton et al. [63] also found a high reported prevalence of redwater in a survey of cattle farms in the south-west, with $66 \%$ of farms reporting ticks also reporting redwater. Redwater is endemic to the UK, but clinical cases are generally only apparent when there is a breakdown in population immunity [9]. Cases may be more prevalent in the southwest because of less consistent contact between cattle and ticks, resulting in occasions where cattle are unexposed at a younger age, but are then later grazed on tick infested pastures. Further investigation of seroprevalence in cattle, the prevalance of $B$. divergens in questing ticks and the management factors that lead to a higher redwater risk in this area, is required.

Relatively high levels of variation in the number of cases of tick-borne diseases across regions has been demonstrated previously [64]. Using records of bovine 
Table 1 The location (latitude and longitude), radius (km), number of respondents, tick prevalence and relative risk for significant clusters of cases of farms with tick infestation in sheep and cattle, as identified by SaTScan ${ }^{\text {TM }}$ analysis of data from a retrospective questionnaire survey in Great Britain

\begin{tabular}{|c|c|c|c|c|c|}
\hline Farm & $\begin{array}{l}\text { Cluster location (lat/long of cluster } \\
\text { centroid) }\end{array}$ & Cluster radius (km) & $\begin{array}{l}\text { No. of respondents in } \\
\text { cluster }\end{array}$ & Tick prevalence (\%) & Relative risk \\
\hline \multirow[t]{4}{*}{ Sheep } & NWales*** $(52.94,-4.43)$ & 57.23 & 23 & 65.2 & 5.43 \\
\hline & NW England ${ }^{* *}(54.41,-3.43)$ & 44.45 & 21 & 66.7 & 5.49 \\
\hline & SW Scotland* $(55.33,-5.69)$ & 70.16 & 5 & 100 & 7.52 \\
\hline & N Scotland $(56.48,-5.98)$ & 103.29 & 17 & 58.8 & 4.62 \\
\hline \multirow[t]{3}{*}{ Cattle } & NWales*** $(52.94,-4.43)$ & 57.23 & 24 & 54.2 & 7.79 \\
\hline & NW England*** $(54.29,-3.26)$ & 46.32 & 29 & 48.3 & 7.03 \\
\hline & W Scotland** $(55.48,-5.98)$ & 103.29 & 5 & 100 & 12.78 \\
\hline
\end{tabular}

${ }^{*} P<0.05,{ }^{* *} P<0.01,{ }^{* * *} P<0.001$

babesiosis and anaplasmosis available from the Norwegian cattle and sheep health recording systems for 20062015, the incidences of livestock diseases were shown to be lower in eastern compared to western Norway.

Table 2 Risk factors for tick infestation on farms, included in logistic regression models, for sheep $(n=480)$ and cattle $(n=$ 711) farms based on data from a retrospective questionnaire survey in Great Britain, showing the coefficient estimate \pm standard error and the odds ratio ( $\pm 95 \%$ confidence interval)

\begin{tabular}{|c|c|c|c|}
\hline Farm & Risk factor & $\begin{array}{l}\text { Coefficient } \\
\text { estimate ( } \pm \text { SE) }\end{array}$ & Odds ratio $(95 \% \mathrm{Cl})$ \\
\hline \multirow[t]{11}{*}{ Sheep } & Terrain*** & & \\
\hline & Lowland & - & 1.00 \\
\hline & Upland*** & $1.92(0.43)$ & $6.84(3.04-16.90)$ \\
\hline & Flock size $(\log 10)^{* * *}$ & $1.37(0.39)$ & $3.94(1.88-8.80)$ \\
\hline & Region* & & \\
\hline & C England & - & 1.00 \\
\hline & Wales & $0.44(0.81)$ & $1.56(0.37-10.69)$ \\
\hline & N England & $1.11(0.80)$ & $3.03(0.77-20.30)$ \\
\hline & E England & $1.17(1.06)$ & $3.22(0.35-29.58)$ \\
\hline & Scotland & $1.02(0.82)$ & $2.77(0.65-19.21)$ \\
\hline & SW England* & $2.0(0.82)$ & $7.13(1.68-49.64)$ \\
\hline \multirow[t]{12}{*}{ Cattle } & Terrain* & & \\
\hline & Lowland & - & 1.00 \\
\hline & Upland* & $0.89(0.39)$ & $2.44(1.15-5.36)$ \\
\hline & Livestock type $e^{* *}$ & & \\
\hline & Cattle only & - & 1.00 \\
\hline & Cattle and sheep** & $1.26(0.47)$ & $3.53(1.51-9.69)$ \\
\hline & Region** & & \\
\hline & $C+$ E England & - & 1.00 \\
\hline & Wales & $0.99(0.83)$ & $2.68(0.60-18.80)$ \\
\hline & N England & $2.61(0.81)$ & $2.61(0.63-17.69)$ \\
\hline & Scotland & $1.45(0.82)$ & $4.26(0.10-29.32)$ \\
\hline & SW England** & $2.27(0.77)$ & $9.68(2.61-62.82)$ \\
\hline
\end{tabular}

${ }^{*} P<0.05,{ }^{* *} P<0.01,{ }^{* * *} P<0.001$

Note: 'Upland' refers to regions classified as Less Favoured Areas and characterized by rough grazing, heathland and moorland [55]
Climate and the much lower populations of sheep and cattle in the east were considered to contribute to this pattern [64]. In contrast, qualitative assessment of redwater cases reported in a survey of Irish farmers and veterinary practitioners found no observable foci of infection [9]. However, spatial statistics quantifying risk are necessary to elucidate spatial patterns which are not obvious based on qualitative assessment alone and correct for sampling bias [65]. The underlying distribution of respondents can vary for a number of reasons, such as sample selection bias due to differences in response rates between regions or farming sectors, or simply due to the underlying distribution of farms, which may lead to false conclusions of "hot spots" for infection in regions of high farm density based on qualitative assessment alone. The analyses applied to the data here provide robust statistical estimates of the spatial distribution of risk, taking into account the potential spatial bias of respondents through applying a presence/absence design.

When analysing risk, it is important to consider the effects of spatial scale [66]. When considered on a continuous scale in the spatial analysis, cases in southwest England were not significantly clustered, but the southwest was significantly associated with tick presence in the multivariable analysis (Table 2). The high tick prevalence in this region cannot be explained by the other factors in the models. Mapping on the relatively broad scale used here may not detect fine-grained variations in risk [66], but at this scale results are buffered against variations in microclimate which affect tick distribution on a local scale [67], allowing relative risk to be assessed in relation to broader trends, such as host density and the macroclimate [26]. Host densities and climatic variables were not directly included in the models however, so it is important to note that factors that appear as significant correlates of tick and TBD prevalence may be proxies for these more-influential drivers. 

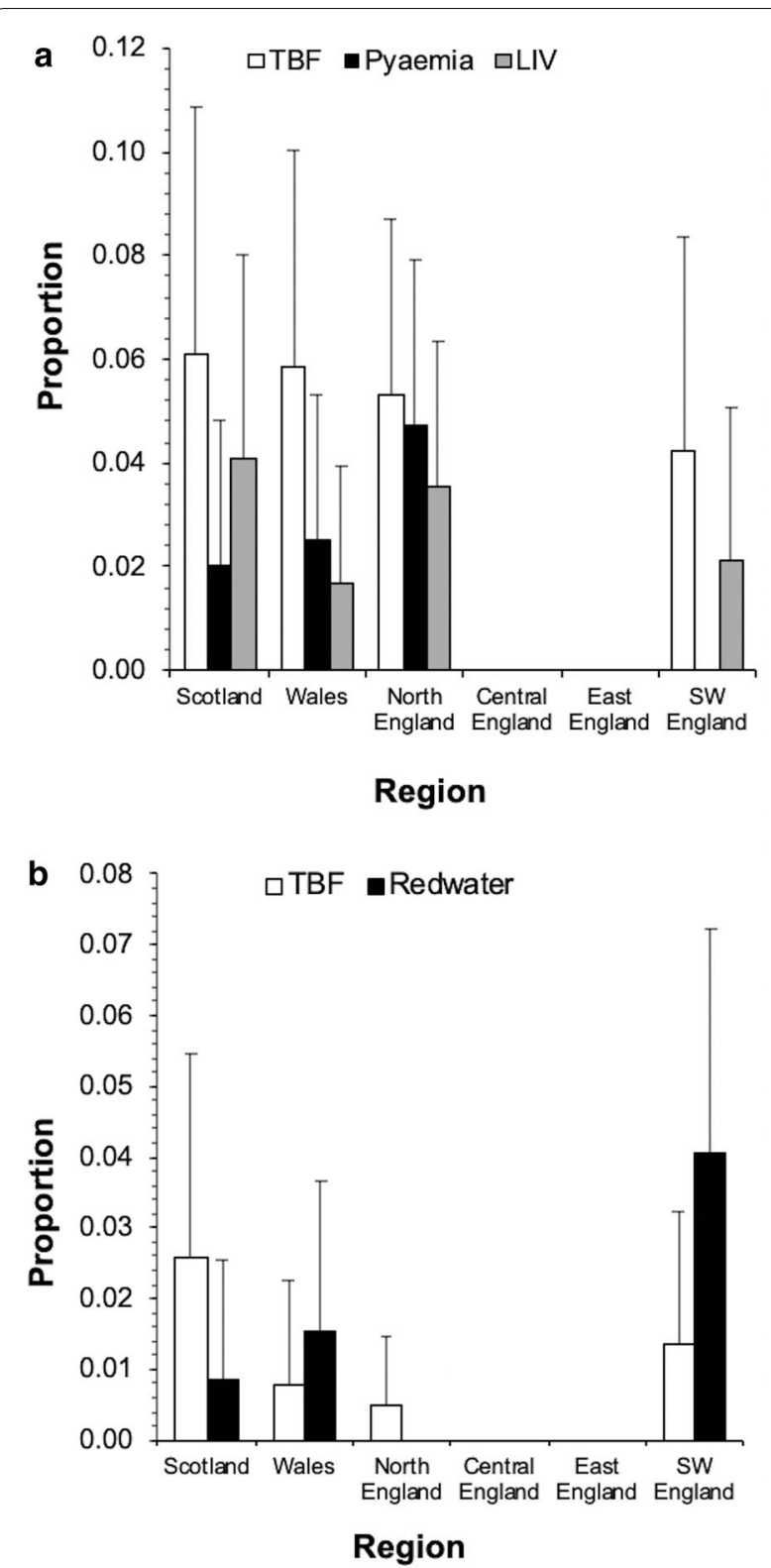

Fig. 4 The percentage ( \pm 95\% confidence intervals) of regional farm respondents to a retrospective questionnaire survey in Great Britain reporting tick-borne disease for sheep (a) and cattle (b)
Some caution is also required with questionnaire surveys. Although they allow the collection of large data sets, they rely on accurate reporting by farmers. Reporting tick presence requires farmers to be aware of what ticks are and to be in close enough contact with livestock to spot their presence. The higher reported tick prevalence in sheep compared to cattle, for example, may be associated, to some degree, with the more frequent handling of sheep compared to beef cattle. Similarly, in terms of TBD, it is likely that farmers are under-diagnosing and may be misinterpreting clinical signs; notably, overall farmers reported that only around $11 \%$ of reported TBD cases were confirmed by a veterinarian or laboratory and two farms reported the presence of redwater in sheep, despite this not being an ovine disease. It should also be noted that this study excluded farms with relatively small numbers of animals, specifically to exclude smallholders and 'hobby farmers', since they might not be representative of commercial husbandry practices. However, the proportion of such holdings varies across the country, which may affect the contributions of these animals to the overall landscape prevalence of ticks and TBD. This possibility requires further investigation.

Effective control in "hot spot" regions, treating livestock with insecticides so that they act as "lethal traps", may result in reduced tick attachment, not just to livestock, but also to other tick hosts [56, 68]. Upland farming areas represent $74 \%$ of the UK's national parks [55], therefore the areas of elevated risk to livestock include areas of high potential contact between people and ticks. Effective control of ticks on livestock, particularly sheep in these areas, could reduce the risk of tick bites in the human population and minimise Lyme disease transmission via ticks co-feeding on sheep [59]. Treatment of livestock hosts has been shown to be effective in reducing disease risk to other hosts in LIV disease models, when deer populations are low [69]. However, overuse of insecticides with this strategy is also likely to hasten the selection for resistance, so alternative methods of tick control, such as the use of resistant or resilient breeds or pasture spelling, may be more appropriate [12,31], although care should be taken if population immunity is suspected.

Table 3 The location (latitude and longitude), radius ( $\mathrm{km}$ ), number of respondents, disease prevalence and relative risk for significant clusters of tick-borne pyaemia cases in sheep and redwater in cattle, as identified by SaTScan ${ }^{\mathrm{TM}}$ analysis of data from a retrospective questionnaire survey in Great Britain

\begin{tabular}{|c|c|c|c|c|c|}
\hline Disease cluster & $\begin{array}{l}\text { Cluster location (lat/long of cluster } \\
\text { centroid) }\end{array}$ & Cluster radius (km) & Number in cluster & $\begin{array}{l}\text { Disease prevalence } \\
(\%)\end{array}$ & Relative risk \\
\hline Pyaemia in sheep & NW England* $(54.29,-3.26)$ & 31.19 & 15 & 33.3 & 25.29 \\
\hline Redwater in cattle & SW England* $(50.38,-4.00)$ & 139.79 & 109 & 6.4 & 21.35 \\
\hline
\end{tabular}

$* P<0.05$ 


\section{Conclusions}

In conclusion, tick infestation was unevenly distributed across Great Britain, with areas of significantly elevated risk in north Wales, northwest England and western Scotland. The prevalence of ticks on farms in "hotspot" clusters ranged between 48-100\%. Upland farming, larger flock sizes and being located in southwest England were found to be significant risk factors for tick presence for sheep. For cattle, significant risk factors were upland farming, being located in southwest England and the presence of sheep on cattle farms. These data have important implications for assessing both the risk of tick-borne disease in livestock and optimising approaches to disease management. In particular, these data highlight the need for effective livestock tick control in upland regions and the southwest and give evidence for the importance of sheep as tick maintenance hosts in Great Britain.

\section{Supplementary information}

Supplementary information accompanies this paper at https://doi. org/10.1186/s13071-020-04287-9.

Additional file 1: Text S1. Retrospective ectoparasite questionnaire survey sent to sheep and cattle farmers in Great Britain.

\section{Acknowledgements}

We would like to thank Sean Richies at MSD for his support and advice and all the farmers who took the time to respond to this questionnaire survey.

\section{Authors' contributions}

$\mathrm{KL}$ designed, undertook the study and wrote the manuscript under the supervision of RW. KL analysed the data with the advice of HRV. All authors read and approved the final manuscript.

\section{Funding}

This work was funded by MSD Animal Health and the Bristol Centre for Agricultural Innovation.

\section{Availability of data and materials}

The datasets generated and/or analysed during the present study are not publicly available in accordance with the data protection act, but anonymised data are available from the corresponding author upon request.

\section{Ethics approval and consent to participate}

It was made clear to questionnaire respondents that all information supplied would be kept strictly confidential and securely disposed of in accordance with the data protection act and that all data would be summarised so that no farm would be individually identifiable. This study was carried out with the approval of the University of Bristol Ethics Committee: UB/18/073.

\section{Consent for publication}

Not applicable.

\section{Competing interests}

The authors declare that they have no competing interests.

\section{Author details}

${ }^{1}$ School of Biological Sciences, University of Bristol, Bristol BS8 1TQ, UK.

${ }^{2}$ Department of Infection and Microbiome, Institute of Infection, Veterinary and Ecological Sciences, University of Liverpool, Liverpool, UK.
Received: 5 May 2020 Accepted: 3 August 2020

Published online: 10 August 2020

\section{References}

1. Gilbert L. Louping ill virus in the UK: a review of the hosts, transmission and ecological consequences of control. Exp Appl Acarol. 2016:68:363-74.

2. Zintl A, Mulcahy G, Skerrett HE, Taylor SM, Gray JS. Babesia divergens, a bovine blood parasite of veterinary and zoonotic importance. Clin Microbiol Rev. 2003;16:622-36.

3. Milne A. The ecology of the sheep tick Ixodes ricinus: spatial distribution. Parasitology. 1950;40:35-45.

4. Jameson L, Medlock J. Tick surveillance in Great Britain. Vector Borne Zoonotic Dis. 2011;11:403-12.

5. Gilbert L, Aungier J, Tomkins JL. Climate of origin affects tick (Ixodes ricinus) host-seeking behavior in response to temperature: implications for resilience to climate change? Ecol Evol. 2014;4:1186-98.

6. Randolph SE. The impact of tick ecology on pathogen transmission dynamics. In: Bowman AS, Nuttall PA, editors. Ticks: Biology, Disease and Control. Cambridge: Cambridge University Press; 2008. p. 40-72.

7. Cayol C, Koskela E, Mappes T, Siukkola A, Kallio ER. Temporal dynamics of the tick /xodes ricinus in northern Europe: epidemiological implications. Parasit Vectors. 2017;10:166.

8. Brodie A. Some aspects of tick-borne fever in sheep. PhD Thesis, University of Glasgow, UK; 1985

9. Zintl A, McGrath G, O'Grady L, Fanning J, Downing K, Roche D, et al. Changing incidence of bovine babesiosis in Ireland. Ir Vet J. 2014;67:19.

10. Boyard C, Vourc'h G, Barnouin J. The relationships between Ixodes ricinus and small mammal species at the woodland-pasture interface. Exp Appl Acarol. 2008;44:61-76.

11. Pietzsch ME, Medlock JM, Jones L, Avenell D, Abbott J, Harding P, et al. Distribution of Ixodes ricinus in the British Isles: investigation of historical records. Med Vet Entomol. 2005:9:306-14.

12. Steele GM, Randolph SE. An experimental evaluation of conventional control measures against the sheep tick, Ixodes ricinus (L.) (Acari: Ixodidae). I. A unimodal seasonal activity pattern. Bull Entomol Res. 1985:75:489-500.

13. Randolph SE. Tick-borne disease systems emerge from the shadows: the beauty lies in molecular detail, the message in epidemiology. Parasitology. 2009;136:1403-13.

14. Stuen S, Granquist EG, Silaghi C. Anaplasma phagocytophilum - a widespread multi-host pathogen with highly adaptive strategies. Front Cell Infect Microbiol. 2013;3:31.

15. Woldehiwet Z. The natural history of Anaplasma phagocytophilum. Vet Parasitol. 2010;167:108-22.

16. Jeffries CL, Mansfield KL, Phipps LP, Wakeley PR, Mearns R, Schock A, et al. Louping ill virus: an endemic tick-borne disease of Great Britain. J Gen Virol. 2014;95:1005-14.

17. Gao F, Jiang R, Hussain H, Venugopal K, Gritsun S, Reid W, et al. Sequencing and antigenic studies of a Norwegian virus isolated from encephalomyelitic sheep confirm the existence of louping ill virus outside Great Britain and Ireland. J Gen Virol. 1993;74:109-14.

18. Macleod J, Gordon WS. Studies in tick-borne fever of sheep. I. Transmission by the tick, Ixodes ricinus, with a description of the disease produced. Parasitology. 1933;25:273-83.

19. Foggie A. Studies on the relationship of tick-bite to tick pyaemia of lambs. Ann Trop Med Parasitol. 1959;53:27-34.

20. Jameson LJ, Medlock JM. Results of HPA tick surveillance in Great Britain. Vet Rec. 2009;165:154

21. Tulloch JSP, Semper AE, Brooks TJG, Russell K, Halsby KD, Christley RM, et al. The demographics and geographic distribution of laboratoryconfirmed Lyme disease cases in England and Wales (2013-2016): an ecological study. BMJ Open. 2019;9:e028064.

22. Abdullah S, Helps C, Severine T, Hannah N, Richard W. Ticks infesting domestic dogs in the UK: a large-scale surveillance programme. Parasit Vectors. 2016:9:391.

23. Davies S, Abdullah S, Helps C, Tasker S, Newbury H, Wall R. Prevalence of ticks and tick-borne pathogens: Babesia and Borrelia species in ticks infesting cats of Great Britain. Vet Parasitol. 2017;244:129-35. 
24. Tulloch J, McGinley L, Sánchez-Vizcaíno F, Medlock JM, Radford A. The passive surveillance of ticks using companion animal electronic health records. Epidemiol Infect. 2017;145:2020-9.

25. Scharlemann JPW, Johnson PJ, Smith AA, Macdonald DW, Randolph SE. Trends in ixodid tick abundance and distribution in Great Britain. Med Vet Entomol. 2008;22:238-47.

26. Dobson ADM, Taylor JL, Randolph SE. Tick (Ixodes ricinus) abundance and seasonality at recreational sites in the UK: hazards in relation to fine-scale habitat types revealed by complementary sampling methods. Ticks Tick Borne Dis. 2011;2:67-74

27. Estrada-Peña A, Gray JS, Kahl O, Lane RS, Nijhof AM. Research on the ecology of ticks and tick-borne pathogens-methodological principles and caveats. Front Cell Infect Microbiol. 2013;3:29.

28. Miles V. Tick infestation of sheep in south west England. Unpublished: University of Bristol; 2014

29. Perrin LD. Exploration of the spatial epidemiology of tick-borne pathogens of livestock in Southern Cumbria. eThesis: University of Salford; 2017.

30. Milne CE, Dalton GE, Stott AW. Integrated control strategies for ectoparasites in Scottish sheep flocks. Livest Sci. 2007;106:243-53.

31. Walker A. Eradication and control of livestock ticks: biological, economic and social perspectives. Parasitology. 2011;138:945-59.

32. Map of Agriculture. 2018. https://mapof.ag/uk/. Accessed 28 Sep 2018.

33. AHDB. UK Sheep Yearbook. 2018. http://beefandlamb.ahdb.org.uk/wpcontent/uploads/2018/10/UK-Sheep-Yearbook-2018.pdf. Accessed 15 Mar 2019.

34. AHDB. UK Cattle Yearbook. 2018. http://beefandlamb.ahdb.org.uk/wpcontent/uploads/2018/10/UK-Cattle-Yearbook-2018.pdf. Accessed 15 Mar 2019.

35. Milnes AS, Green LE. Prevalence of lice on dairy cattle in England and the bordering counties of Wales. Vet Rec. 1999:145:357-62.

36. Bisdorff B, Milnes A, Wall R. Prevalence and regional distribution of scab, lice and blowfly strike in Great Britain. Vet Rec. 2006;158:749.

37. Thrusfield M, Ortega C, de Blas I, Noordhuizen JP, Frankena K. WIN EPISCOPE 2.0: improved epidemiological software for veterinary medicine. Vet Rec. 2001;148:567.

38. AHDB. Sheep Health and Welfare Report. 2018. http://beefandlamb.ahdb. org.uk/wp-content/uploads/2018/11/SHAWG-REPORT_2018_11_19_ WEB.pdf. Accessed 10 May 2019

39. AHDB. Fourth Report: GB Cattle Health and Welfare Group. 2018. https:// projectblue.blob.core.windows.net/media/Default/Beef \& Lamb/CHAWG/ CHAWG-Fourth-Report-2018.pdf. Accessed 10 May 2019.

40. Department for Environment and Rural Affairs (DEFRA). Farming Statistics - Livestock Populations. 2017. https://assets.publishing.service.gov.uk/ government/uploads/system/uploads/attachment_data/file/689711/ structure-dec17-ukseries-15mar18.pdf. Accessed 20 May 2019.

41. R Development Core Team. R: A language and environment for statistical computing. Vienna: R Foundation for Statistical Computing; 2019. https:// www.R-project.org/.

42. Hope A. A simplified Monte Carlo significance test procedure. J R Stat Soc Series B Stat Methodol. 1968;30:582-98.

43. Postcode Batch Converter | UK Grid Reference Finder. 2020. https://gridr eferencefinder.com/postcodeBatchConverter/. Accessed 3 Mar 2019.

44. Baddeley A, Rubak E, Turner R. Spatial point patterns: methodology and applications with R. London: Chapman and Hall/CRC Press; 2015.

45. Davies T, Marshall J, Hazelton M. Tutorial on kernel estimation of continuous spatial and spatiotemporal relative risk. Stat Med. 2018;37:1191-221.

46. Davies TM, Hazelton ML. Adaptive kernel estimation of spatial relative risk. Stat Med. 2010;29:2423-37.

47. Kulldorff A. Spatial scan statistic. Commun Stat Theory Methods. 1997;26:1481-96.

48. Hosmer DW, Lemeshow S. Applied logistic regression. 2nd ed. New York: John Wiley \& Sons; 2000.

49. Stoltzfus JC. Logistic regression: a brief primer. Acad Emerg Med. 2011;18:1099-104.
50. Sperandei S. Understanding logistic regression analysis. Biochem. Medica. 2014;24:12-8.

51. Fox J, Weisberg S. An R companion to applied regression. Thousand Oaks CA: Sage; 2019 .

52. Prabhakaran S. InformationValue: performance analysis and companion functions for binary classification models. Version 1.2.3; 2016.

53. Cull B, Pietzsch ME, Hansford KM, Gillingham EL, Medlock JM. Surveillance of British ticks: an overview of species records, host associations, and new records of Ixodes ricinus distribution. Ticks Tick Borne Dis. 2018;9:605-14.

54. Medlock JM, Pietzsch ME, Rice NVP, Jones L, Kerrod E, Avenell D, et al. Investigation of ecological and environmental determinants for the presence of questing Ixodes ricinus (Acari: Ixodidae) on Gower. South Wales. J Med Entomol. 2008;45:314-25.

55. Department for Environment and Rural Affairs (DEFRA). Farming in the Uplands. 2010. https://publications.parliament.uk/pa/cm201011/cmsel ect/cmenvfru/writev/556/18.htm. Accessed 29 Jan 2019.

56. Dobson ADM, Randolph SE. Modelling the effects of recent changes in climate, host density and acaricide treatments on population dynamics of Ixodes ricinus in the UK. J Appl Ecol. 2011;48:1029-37.

57. Medlock JM, Jameson LJ, Pietzsch M, Gilbert L. British ticks. Br Wildl. 2009;20:258-66.

58. Gilbert L. Altitudinal patterns of tick and host abundance: a potential role for climate change in regulating tick-borne diseases? Oecologia. 2010;162:217-25.

59. Ogden NH, Nuttall PA, E RS. Natural Lyme disease cycles maintained via sheep by co-feeding ticks. Parasitology. 1997;115:591-9.

60. Evans $\mathrm{G}$. The distribution and economic importance of Ixodes ricinus (L) in Wales and the Welsh border counties with special reference to N.W. Cardiganshire. Bull Entomol Res. 1951;41:469-85.

61. Coipan EC, Jahfari S, Fonville M, Maassen CB, van der Giessen J, Takken $W$, et al. Spatiotemporal dynamics of emerging pathogens in questing Ixodes ricinus. Front Cell Infect Microbiol. 2013;3:36.

62. European Centre for Disease Prevention and Control and the European Food Safety, Authority. The importance of vector abundance and seasonality: results from an expert consultation. 2018. https://ecdc.europa.eu/ en/publications-data/importance-vector-abundance-and-seasonality. Accessed 10 Sep 2019.

63. Barton CH, Dale EF, Dixon C, Coles GC. Survey of parasite control on beef farms in south-west England. Vet Rec. 2006;159:682-4.

64. Mysterud A, Stigum VM, Seland IV, Herland A, Easterday WR, Jore S, et al. Tick abundance, pathogen prevalence, and disease incidence in two contrasting regions at the northern distribution range of Europe. Parasit Vectors. 2018;11:309.

65. Chivers CA, Vineer HR, Wall R. The prevalence and distribution of sheep scab in Wales: a farmerquestionnaire survey. Med Vet Entomol. 2018;32:244-50.

66. Daniel M, Koláŕ J, Zeman P. GIS tools for tick and tick-borne disease occurrence. Parasitology. 2004;129(Suppl. 7):329-52.

67. Randolph SE. Tick ecology: processes and patterns behind the epidemiological risk posed by ixodid ticks as vectors. Parasitology. 2004;129(Suppl.):37-65.

68. Newborn D, Baines D. Enhanced control of sheep ticks in upland sheep flocks: repercussions for red grouse co-hosts. Med Vet Entomol. 2012;26:63-9.

69. Porter R, Norman RA, Gilbert L. A model to test how ticks and louping ill virus can be controlled by treating red grouse with acaricide. Med Vet Entomol. 2013;27:237-46.

\section{Publisher's Note}

Springer Nature remains neutral with regard to jurisdictional claims in published maps and institutional affiliations. 